\title{
A CASE STUDY ON STABILIZATION AND REUSE OF GEOPOLYMER-ENCAPSULATED BROWN COAL FLY ASH
}

\author{
P. BANKOWSKI ${ }^{1}$, L. ZOU ${ }^{1} \&$ R. HODGES ${ }^{2}$ \\ ${ }^{1}$ School of Engineering and Technology, Deakin University, Geelong, Victoria, Australia. \\ ${ }^{2}$ School of Applied Science, Monash University, Churchill, Victoria, Australia.
}

\begin{abstract}
Fly ash disposal for coal power stations is an ongoing problem. This paper explores the use of a geopolymeric material to stabilize fly ash and reduce the leach rates of metals, and at the same time determine whether the stabilized material can be reused and recycled as value-added products. Fly ash from the Latrobe Valley, Victoria, Australia, was collected and stabilized in a geopolymer with a molar silica to alumina ratio of 3 . Fly ash was collected from electrostatic precipitators [precipitator fly ash (PFA)] and ash disposal ponds [leached fly ash (LFA)] so that a comparison in results between the two types could be made. In terms of stabilization of selected heavy metals, PFA showed better trends towards reduction in leach rates, although for this fly ash the initial concentration of heavy metals is low. LFA showed better trends towards reduction in major elemental leach rates. Compressive strength tests were carried out to determine the potential of the material to be used as recycled products. A maximum compressive strength of $32 \mathrm{MPa}$ was achieved with a PFA-geopolymer combination, which shows that these materials can be recycled and reused. However, more research is still required to achieve greater compressive strengths. Scanning electron microscopy linked the leaching behaviour and compressive strength values with images that showed the fly ash particle-geopolymer interaction. Materials cost estimation was conducted to determine the cost of materials required to stabilize and reuse fly ash geopolymers.

Keywords: fly ash, material costs, metal leaching, stabilization, waste management.
\end{abstract}

\section{INTRODUCTION}

Waste management for most industries has become an important issue such that in most cases thousands of dollars are spent each year for the treatment of industrial waste. The Latrobe Valley in the state of Victoria, Australia, has four brown coal fired power stations which consume thousands of tonnes of low-rank brown coal daily. This practice produces large quantities of fly ash each day. Fly ash is a waste generated from the burning of coal and consists of silicates, minerals and oxides of metals and heavy metals, which are not combustible, and are carried in the stack gases of the boilers. The disposal of fly ash has always been of concern to these companies.

This research addresses the issue of disposal and recycling of fly ash from one of the power stations in the Latrobe Valley. Currently the fly ash is electrostatically precipitated from the stack gas, stored in hoppers, then sluiced and pumped to specially designed ash ponds for storage. Once the service life of the ash ponds has been reached, the ponds are rehabilitated and replanted, and a new ash pond is constructed. However, available land for new ash ponds is decreasing and will ultimately become exhausted. Due to the nature of the fly ash and environmental regulations, its disposal in regular landfills is not permitted. The fly ash must be treated or stabilized in a manner that renders if safe from leaching before disposal.

There are many options available to treat and stabilize fly ash, and stabilization can sometimes lead to producing value-added products. Brown coal fly ash can be added to cement $[1,2]$ and can also be used as a soil conditioner by replacing minerals and elements required by plants $[1,3]$. This research explores the use of geopolymeric materials to stabilize fly ash. Geopolymers, in pure form, have similar properties to cement and brick, and as a result can be used in a variety of applications from construction to waste stabilization. By the stabilization of the fly ash new materials are produced that 
could potentially have the same applications as cement, so this research also explores the suitability of reuse of the new materials as value-added products. Using geopolymers as the stabilization media, a safe material could be produced, and by altering the percentage of fly ash added to the geopolymer, a value-added product can be made and sold to recover the costs of stabilization.

\section{BACKGROUND}

Geopolymers are polymeric materials that are analogous to carbon-based polymers; however, they have a structure based on alumina and silica units rather than carbon. Their synthesis involves the use of aluminosilicate rich materials, such as clays, that dissolve under highly alkaline conditions. The high $\mathrm{pH}$ partially dissolves particles and liberates alumina and silica monomers that polycondense though a series of oligomers to produce an amorphous three-dimensional inorganic structure [4]. The alkali solution not only dissolves the alumina and silica precursors but also hydrolyses the surface of the aluminosilicate particles allowing reactions to occur between the already dissolved silicate species and the particle surface [5]. The presence of cations $\left(\mathrm{Na}^{+}, \mathrm{K}^{+}\right.$and $\left.\mathrm{Ca}^{2+}\right)$ balances the charges caused by $\mathrm{Al}^{3+}$ being present in fourfold coordination and catalyses the reaction. The reaction can be described as:

$$
\begin{aligned}
& \begin{array}{c}
\left(\mathrm{Si}_{2} \mathrm{O}_{5}, \mathrm{Al}_{2} \mathrm{O}_{2}\right)_{n}+n \mathrm{SiO}_{2}+n \mathrm{H}_{2} \mathrm{O} \longrightarrow n(\mathrm{OH})_{3}-\mathrm{Si}-\mathrm{O}-\mathrm{Al}^{-}-(\mathrm{OH})_{3} \\
(\mathrm{OH})_{2}
\end{array}
\end{aligned}
$$

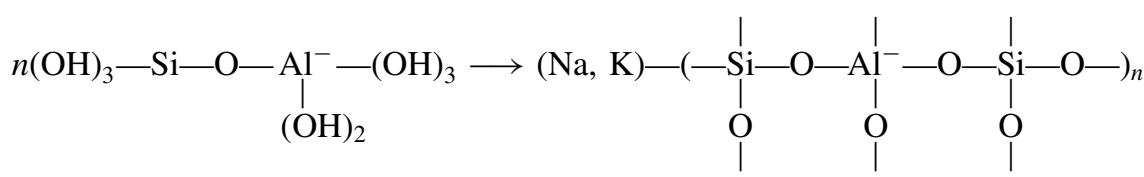

and produces the proposed structure shown in Fig. 1 .

Geopolymers are adaptable materials that can be used for a wide variety of applications. The raw materials used in their manufacture can be obtained from virgin or recycled wastes containing alumina and silica. In recent studies black coal fly ash, builders' waste [7, 8], clays [9], slags [10] and aluminosilicate minerals [11] have been used as a basis for geopolymerization.

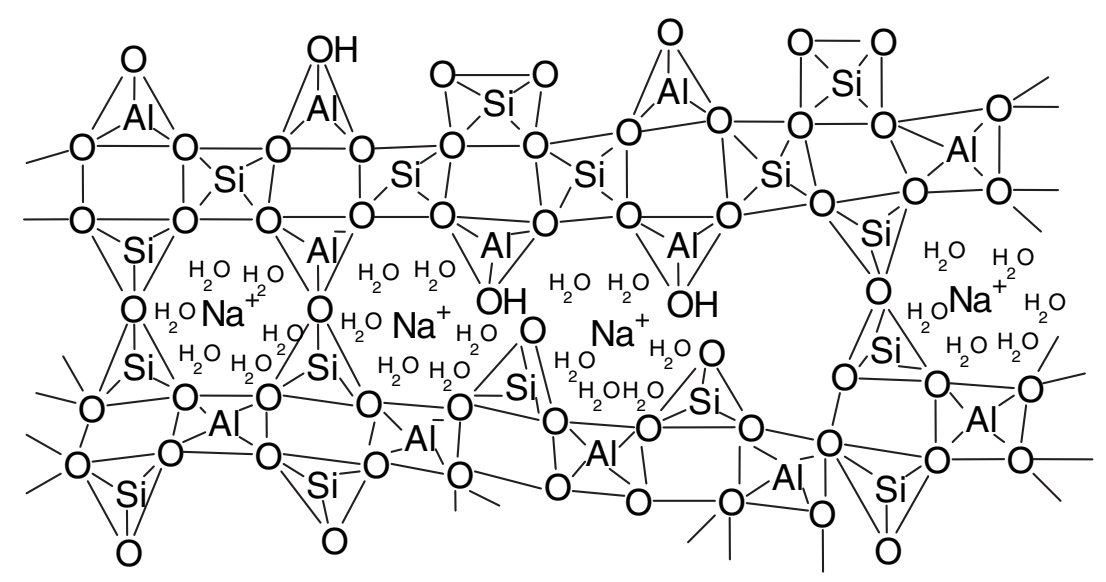

Figure 1: Structure of a sodium-based geopolymer [6]. 
In terms of waste stabilization they function similar to cement binders, but have improved chemical and physical properties. The mechanisms of encapsulation are believed to be either physical or chemical, where metals are taken into the geopolymer network and bound into the structure for charge balancing roles or physically trapped in the network [12]. Radioactive waste encapsulation by geopolymers has received attention as an alternative to ordinary Portland cement. Khalil and Merz studied intermediate level wastes and found that waste loading should be below $50 \mathrm{wt} \%$ of the reactive components or the geopolymer will fail to cure [13]. Promising results were also obtained by Palomo with successful encapsulation of samples spiked with chromium, lead and boron [14, 15].

\section{EXPERIMENTAL}

\subsection{Materials}

The fly ash used for the synthesis of geopolymer structures was obtained from Latrobe Valley, Victoria, Australia, and is of brown coal origin. Precipitator fly ash (PFA) was collected from the hoppers of electrostatic precipitators while leached fly ash (LFA) was collected from ash disposal ponds. LFA is the disposed form of PFA after it has been sluiced, transported and stored in ash disposal ponds. It has been in contact with water and is of a moist consistency. HR 1 grade kaolin clay used in this study was obtained from Unimin Australia Pty Ltd. The major chemical composition of the PFA, LFA and kaolin are shown in Table 1 and were obtained using X-ray fluorescence (Phillips PW1660). Analytical grade sodium hydroxide was used in pellet form. Sodium silicate solution was obtained from PQ Australia and consists of a 2:1 molar ratio of silica to sodium oxide. The same batch materials were used for all experiments and distilled water was used throughout.

\subsection{Sample preparation}

Sixteen $750 \mathrm{~g}$ samples were prepared ranging from $10 \mathrm{wt} \%$ fly ash-90wt $\%$ geopolymer to $80 \mathrm{wt} \%$ fly ash-20wt $\%$ geopolymer in $10 \%$ increments. LFA, obtained in moist form, was oven dried at $105^{\circ} \mathrm{C}$ overnight to remove excess moisture. Metakaolin clay was prepared by calcining kaolin at $750^{\circ} \mathrm{C}$ for $10 \mathrm{~h}$.

Table 1: Composition of raw materials (mass \%).

\begin{tabular}{lccc}
\hline Element & PFA & LFA & Kaolin clay \\
\hline $\mathrm{SiO}_{2}$ & 2.4 & 21.2 & 49.3 \\
$\mathrm{Al}_{2} \mathrm{O}_{3}$ & 1.2 & 4.3 & 35.0 \\
$\mathrm{CaO}$ & 30.6 & 14.9 & 0.1 \\
$\mathrm{MgO}$ & 16.4 & 11.6 & 0.3 \\
$\mathrm{Na}_{2} \mathrm{O}$ & 4.3 & 0.5 & 0.2 \\
$\mathrm{Fe}_{2} \mathrm{O}_{3}$ & 8.2 & 6.4 & 1.1 \\
$\mathrm{~K}_{2} \mathrm{O}$ & 0.3 & 0.2 & 0.2 \\
$\mathrm{TiO}_{2}$ & - & - & 1.1 \\
$\mathrm{SO}_{3}$ & 14.0 & 4.7 & - \\
$\mathrm{Loss}_{3}$ on ignition (LOI) & 22.6 & 36.3 & $12.9\left(1000^{\circ} \mathrm{C}\right)$ \\
\hline
\end{tabular}


Each geopolymer used for stabilization had a molar silica to alumina ratio of 3:1 and the effect of the fly ash on this ratio was ignored. It was assumed that not enough silica would dissolve from the fly ash during synthesis to affect the ratios of reactive components in the geopolymer. An activator solution of sodium silicate, sodium hydroxide and water was prepared. The sodium hydroxide concentration in the solution was $0.6 \mathrm{M}$ and the sodium silicate concentration was $8.74 \mathrm{M}$. Upon dissolution of the sodium hydroxide pellets in the activator solution, the metakaolin clay was added slowly to ensure uniformity. Once the required mass of clay had been added, the mixture was allowed to mix for a further $10 \mathrm{~min}$ to dissolve the metakaolin and produce a geopolymeric paste. Then fly ash was blended in the required percentages, homogenized and the mixture was transferred to moulds and cured. The mass ratio of metakaolin to fly ash is given in Table 2. Polypropylene labware was used throughout the experiments to avoid silica contamination.

Addition of the fly ash into the geopolymer paste caused the mixture to become dry as the percentage of fly ash was increased in each sample. The water content of each sample is shown in Table 2. Samples containing more than $50 \mathrm{wt} \%$ fly ash (less than $21.7 \mathrm{wt} \%$ water) were no longer a paste, but a semi-dry powder and required pressing to consolidate. For this reason two different methods of curing were used once the fly ash-geopolymer mix was prepared. Samples in slurry form were transferred to polypropylene moulds and cured at $65^{\circ} \mathrm{C}$ for $24 \mathrm{~h}$; otherwise the semi-dry form of the mixture was transferred to a die and compressed to $10 \mathrm{MPa}$, removed and allowed to cure at the same conditions. After oven curing, the fly ash-geopolymer composite material was removed from the moulds and allowed to cure for a further 6 days at room temperature, giving a total preparation to testing time of 7 days.

\subsection{Leaching tests}

Each sample was prepared and leached according to the standard USEPA TCLP Method 1311 [16] leaching test. Samples with a total mass of $750 \mathrm{~g}$ were prepared for each combination. Every sample was mixed well to achieve maximum homogeneity. From the $750 \mathrm{~g}$ sample, two $100 \mathrm{~g}$ sub-samples were taken and leached in duplicate, and the average leachate concentration was calculated after analysis. After the test, the solid and liquid phases were separated by centrifuging for $5 \mathrm{~min}$ at $6000 \mathrm{rpm}$. Two hundred and fifty millilitres of supernatant were filtered and acidified with $4 \mathrm{ml}$ of concentrated nitric acid to give a $\mathrm{pH}$ less than 2 for all samples. Glassware, filters, extraction vessels and other equipment were acid washed to avoid metal contamination.

Table 2: Mix design of fly ash-geopolymer samples.

\begin{tabular}{lccc}
\hline Sample & $\begin{array}{c}\text { Fly ash } \\
(\text { mass } \%)\end{array}$ & $\begin{array}{c}\text { Fly ash metakaolin } \\
\text { mass ratio }\end{array}$ & $\begin{array}{c}\text { Water } \\
(\text { mass \%) }\end{array}$ \\
\hline PFA10/LFA10 & 10 & 0.52 & 39.1 \\
PFA20/LFA20 & 20 & 1.27 & 34.7 \\
PFA30/LFA30 & 30 & 2.01 & 30.4 \\
PFA40/LFA40 & 40 & 3.12 & 26.0 \\
PFA50/LFA50 & 50 & 4.79 & 21.7 \\
PFA60/LFA60 & 60 & 7.03 & 17.4 \\
PFA70/LFA70 & 70 & 10.93 & 13.0 \\
PFA80/LFA80 & 80 & 18.74 & 8.7 \\
\hline
\end{tabular}


Analysis of the elements in the leachate solutions was conducted using an inductively coupled plasma-optical emission spectrometer (ICP-OES) (Varian Liberty 200). A small quantity of each sample was initially analysed by inductively coupled plasma-mass spectrometry to give an indication of the typical concentrations of heavy metals in the untreated fly ash and in the stabilized fly ash. Some elements were omitted from further study as their concentrations were below the detection limits. ICP-OES samples were analysed in batches with standards repeated no more than every 15 samples. This allowed for the determination of machine drift and correction for errors.

\subsection{Scanning electron microscopy (SEM) analysis}

SEM was carried out using a Leo 1530 microscope. Samples were mounted in low-viscosity Spurr's resin under vacuum for $8 \mathrm{~h}$. Each mounted sample was ground beginning with 220 grit silicon carbide paper, then progressively through 500 grit, 800 grit and 1200 grit, and polishing with $6 \mu \mathrm{m}, 3 \mu \mathrm{m}$ and $1 \mu \mathrm{m}$ diamond suspensions. Ultrasonic cleaning was performed before polishing and between each stage of polishing to remove contamination. Mounts were carbon coated for imaging.

\subsection{Compressive strength tests}

Samples were prepared according to the above procedure for leaching tests and tested in general accordance with AS/NZS2350.11 [17]. The moulds used measured $40 \times 40 \times 160 \mathrm{~mm}$ for paste samples and $42 \times 42 \times$ height for pressed samples. The material for pressed samples was transferred to a special mould and ram, as a powder, and pressed to $10 \mathrm{MPa}$. The height of each sample depended on the amount of material placed in the mould and every effort was made to keep the samples of the same height, varying by no more than $3 \mathrm{~mm}$.

Compressive tests were carried out on the seventh day of curing, as for leaching tests. Samples from the larger moulds were broken in half using a three-point breaking apparatus to prevent damage to the sample and then compression tested. The $\mathrm{x}$-head speed of the testing machine was $2.4 \mathrm{kN} / \mathrm{s}$ and the maximum compressive strengths were recorded.

\section{RESULTS AND DISCUSSION}

4.1 Mineral composition of brown coal fly ash

The composition of brown coal fly ash greatly differs in comparison to black coal fly ash. PFA contains only $2.4 \mathrm{wt} \% \mathrm{SiO}_{2}$ and $1.2 \mathrm{wt} \% \mathrm{Al}_{2} \mathrm{O}_{3}$ and without another added source of silica and alumina a geopolymeric material could not be formed. The major inorganic oxide constituents in brown coal fly ash are calcium oxide, magnesium oxide, sodium oxide and iron oxide that make approximately $60 \%$ of the total mass (Table 1). The presence of some crystalline phases in unstabilized PFA, such as quartz, calcium sulphate (anhydrite), calcium oxide (lime), magnesium oxide (periclase) and sodium silicate $\left(\mathrm{Na}_{2} \mathrm{SiO}_{3}\right)$, are reflected in X-ray diffraction (XRD) spectra, though the high noise to background ratio indicates the presence of non-crystalline phases (Fig. 2).

\subsection{Leaching tests}

Leaching tests were conducted according to the USEPA TCLP, which simulates the long-term leaching behaviour of elements in waste samples by exposing them to an environment which is 


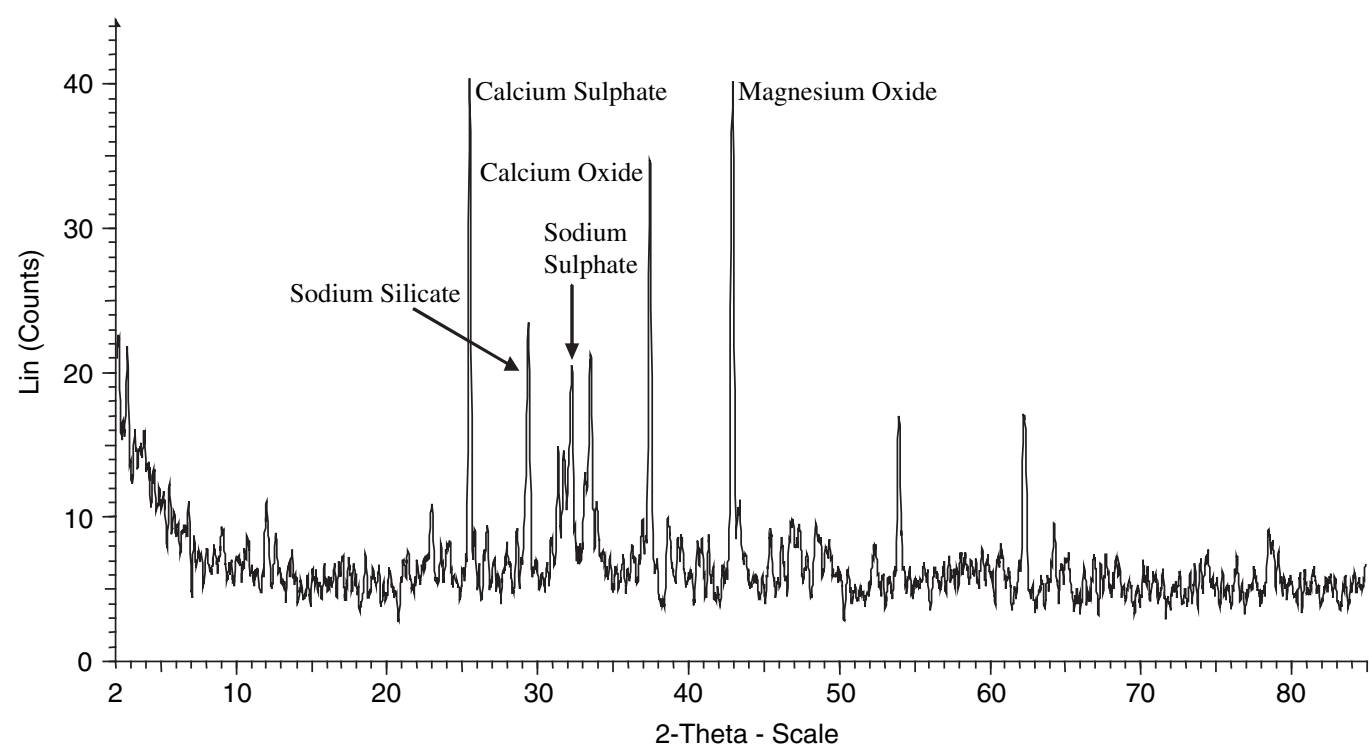

Figure 2: The XRD spectrum of brown coal fly ash.

Table 3: Trace metal leaching from PFA-geopolymer materials $(\mu \mathrm{g} / \mathrm{l})$.

\begin{tabular}{rrrrrrrrr}
\hline \% PFA & Mo & \multicolumn{1}{c}{$\mathrm{Sr}$} & $\mathrm{Ba}$ & $\mathrm{Ni}$ & $\mathrm{Mn}$ & $\mathrm{V}$ & $\mathrm{Zn}$ & $\mathrm{Cu}$ \\
\hline 100 & 110 & 26300 & 221 & n.d. & n.d. & n.d. & n.d. & 17 \\
80 & n.d. & 14404 & 84 & n.d. & n.d. & n.d. & n.d. & n.d. \\
70 & n.d. & 11053 & 68 & n.d. & n.d. & n.d. & 3 & n.d. \\
60 & n.d. & 8068 & 56 & n.d. & n.d. & n.d. & n.d. & n.d. \\
50 & n.d. & 4830 & 12 & n.d. & 2 & n.d. & 16 & n.d. \\
40 & n.d. & 4632 & 14 & 357 & 644 & n.d. & 15 & n.d. \\
30 & n.d. & 3472 & 18 & 279 & 531 & n.d. & 18 & n.d. \\
20 & n.d. & 2242 & 41 & 119 & 165 & 128 & 60 & n.d. \\
10 & n.d. & 888 & 49 & 132 & 205 & 290 & 267 & n.d. \\
\hline
\end{tabular}

n.d., not detected.

more severe than would otherwise be encountered during disposal. Long-term leaching effects are simulated because heavy metals can leach and contaminate surface and ground water bodies when contacted with water. However, one of the favourable characteristics of this fly ash is the low concentration of the strictly regulated heavy metals such as lead, mercury, cadmium and chromium [18]. Initial leaching tests showed that the concentrations of lead, mercury, cadmium and chromium in the leachate of PFA and LFA were below detection limits. In Tables 3 and 4, trace metal analysis from PFA- and LFA-geopolymer samples are given, showing the leach rates of eight elements. Particular attention should be paid to the high leach rate of strontium from untreated PFA and LFA.

For geopolymers synthesized with PFA, metals that showed a decrease in leaching were barium, copper, molybdenum and strontium (Table 3). When the leach rates of stabilized fly ash are compared to the rates of unstabilized fly ash, the results are encouraging. The maximum reduction for barium 
Table 4: Trace metal leaching from LFA-geopolymer materials $(\mu \mathrm{g} / \mathrm{l})$.

\begin{tabular}{rrrrrrrrr}
\hline \% LFA & Mo & \multicolumn{1}{c}{$\mathrm{Sr}$} & $\mathrm{Ba}$ & $\mathrm{Ni}$ & $\mathrm{Mn}$ & $\mathrm{V}$ & $\mathrm{Zn}$ & $\mathrm{Cu}$ \\
\hline 100 & n.d. & 11300 & 147 & n.d. & 500 & n.d. & n.d. & 12 \\
80 & n.d. & 10582 & 118 & n.d. & 498 & n.d. & 5 & n.d. \\
70 & n.d. & 8047 & 109 & n.d. & 255 & n.d. & n.d. & n.d. \\
60 & n.d. & 6925 & 141 & n.d. & 215 & n.d. & 4 & n.d. \\
50 & n.d. & 5414 & 135 & n.d. & 373 & n.d. & n.d. & n.d. \\
40 & n.d. & 4460 & 221 & 63 & 588 & n.d. & n.d. & n.d. \\
30 & n.d. & 2220 & 104 & 48 & 439 & n.d. & 34 & n.d. \\
20 & n.d. & 1416 & 107 & n.d. & 335 & 121 & 32 & 13 \\
10 & n.d. & 636 & 26 & n.d. & 45 & 350 & 37 & 12 \\
\hline
\end{tabular}

n.d., not detected.

was $94 \%$ at $50 \mathrm{wt} \%$ PFA addition, although a slight increase was observed at percentages of fly ash below 50wt\% PFA. Strontium showed good results with reductions as high as $96 \%$ at a PFA addition of $10 \mathrm{wt} \%$. The leach rates of strontium were reduced below the leach rates expected if dilution was simply occurring and there was no stabilization effect from the geopolymer. Copper and molybdenum also showed good results; however, the trends are less obvious since leach rates are reduced to below the detection limits of analysis. The remaining elements analysed increased in leach rates as the percentage of the geopolymer was increased, indicating that perhaps the stabilization of some elements in this fly ash is not favourable using geopolymers as the stabilization method.

The reduction in leach rates of trace metals from LFA geopolymers was also achieved although in a more limited capacity. Those elements which exhibited good reductions in leach rates for PFA geopolymers (barium, copper, molybdenum and strontium) showed less apparent trends (Table 4). The stabilization of strontium was also very successful for LFA geopolymers in comparison to PFA geopolymers, with leach rates being reduced from 11300 to $636 \mu \mathrm{g} / \mathrm{l}$ throughout the range of LFA addition. This equates to a reduction of $94 \%$. The leach rates of barium decreased slightly with increasing addition of geopolymers; however, a significant reduction was not observed until the percentage of LFA was reduced to only $10 \mathrm{wt} \%$. The leach rates of copper, on the other hand, decreased below the detection limits and then increased at low percentages of LFA addition. Molybdenum, which was stabilized successfully in PFA geopolymers, had a leachate concentration that was not detected in untreated LFA. In fact, LFA had consistently lower untreated leach rates compared to PFA.

Overall, the leachate concentrations of many trace elements in PFA and LFA were low, making it difficult to firmly establish whether the geopolymer has played a role in the stabilization of most trace elements. Other factors such as formation of precipitates and complex silicates could be responsible for lower leaching rates. In general, PFA showed better stabilization for trace heavy metals than LFA, although good results have been obtained for most elements.

Leaching tests were also conducted on major elements to understand the system as a whole, even though these elements are not considered as toxic or particularly dangerous to the environment. They serve to provide information about what is occurring in the geopolymer phase on a larger scale. Major elements were selected based on their concentrations in the unstabilized fly ash and their ability to participate in geopolymeric reactions. For this reason, calcium, magnesium, sulphur and potassium were chosen since calcium, magnesium and sulphur make up a large percentage of the fly ash. Potassium and calcium can also participate in geopolymeric reactions. 
As presented previously in the discussion on heavy metal stabilization, there is a trend towards a reduction in leaching as a result of the encapsulation by the geopolymer material. Figures 3 and 4 show the leach rates of the four chosen major elements for the two types of fly ash used in this study. PFA geopolymers showed that they have the ability to significantly reduce the leach rates of calcium

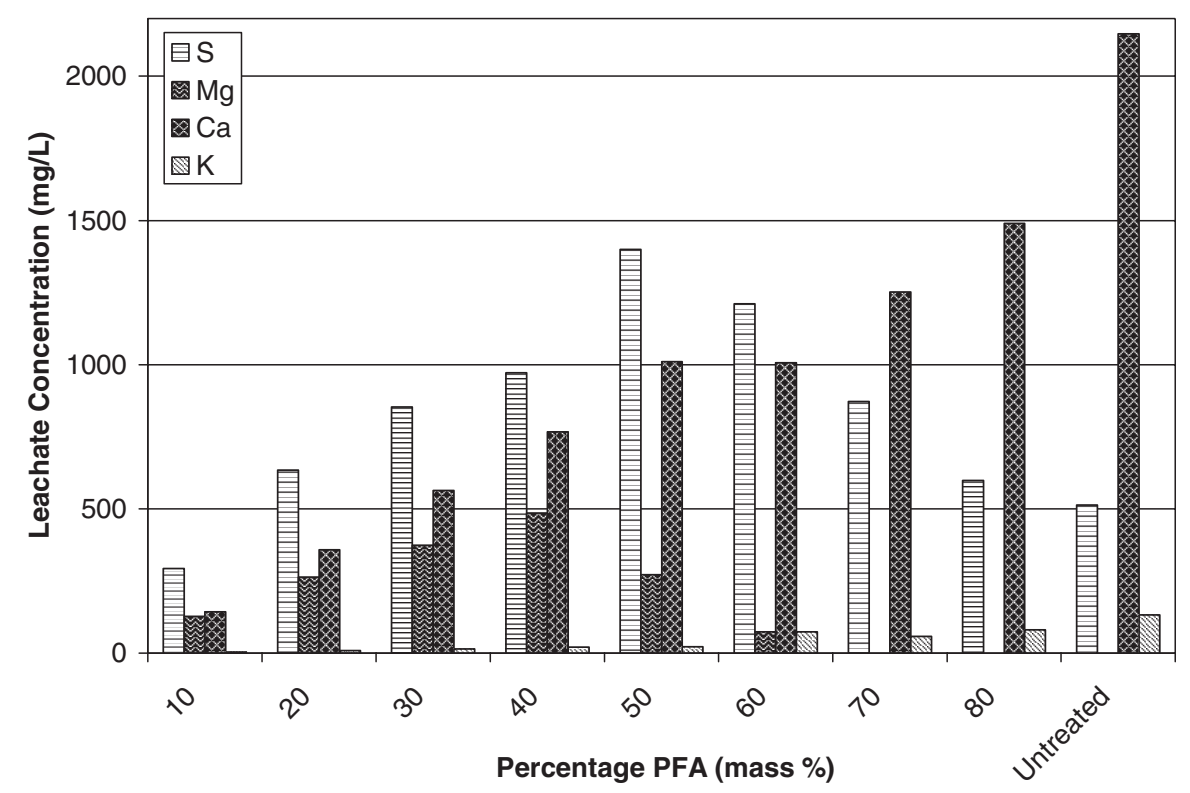

Figure 3: Leach rates of major elements from geopolymer-stabilized PFA.

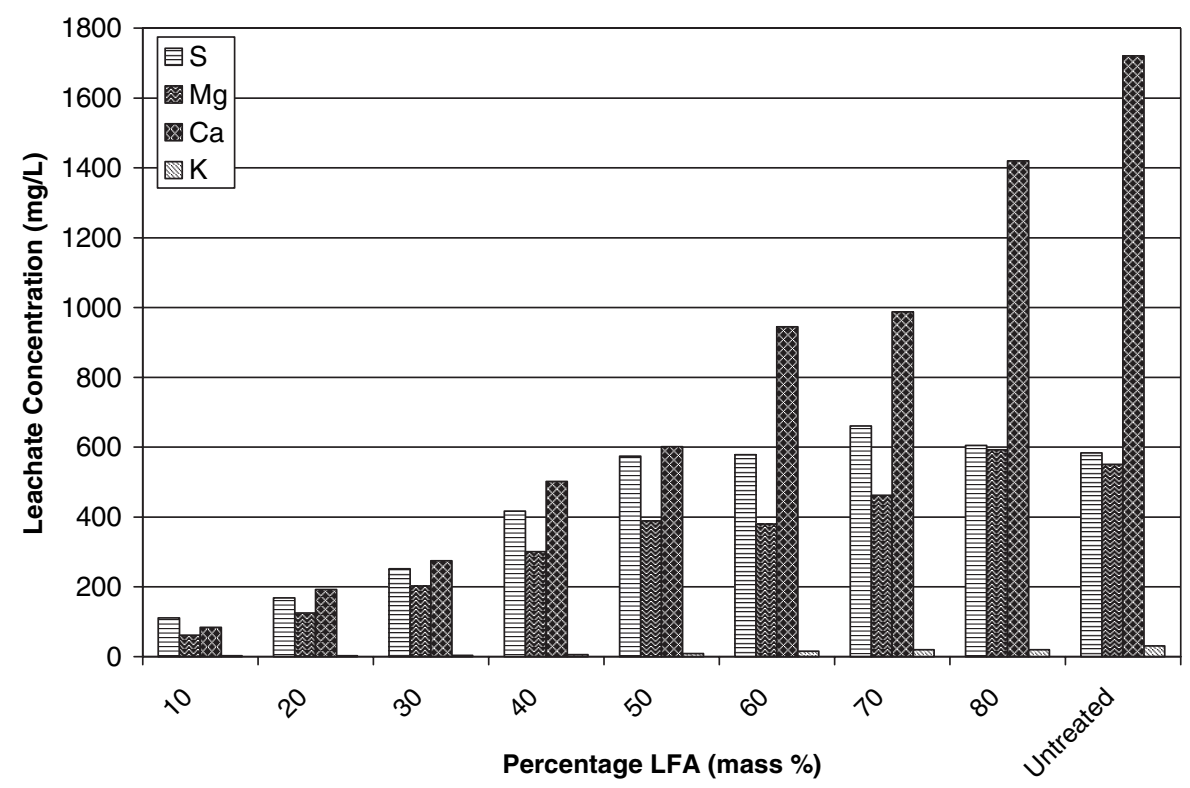

Figure 4: Leach rates of major elements from geopolymer-stabilized LFA. 
and potassium, which is not surprising since these two elements can participate in the geopolymer network in charge balancing roles. The leach rates of magnesium and sulphur increased dramatically over those of untreated PFA before a reduction was observed.

When LFA was stabilized by the geopolymer, the same substantial reduction in leaching of calcium and potassium was observed compared to unstabilized LFA. However, unstabilized LFA showed a higher leach rate of magnesium and sulphur. The leach rates of these two elements were reduced by the addition of the geopolymer, with only a marginal increase observed in the leach rate of sulphur at approximately $70 \mathrm{wt} \%$ LFA. The theory behind the stabilization of elements in geopolymers centres on cations. Anion stabilization has been poorly researched and documented. Cations can participate in charge balancing roles or even covalent bonding and complex formation. Sulphur is present as sulphates in this fly ash, which are anionic. Based on current stabilization principles, there exists less opportunity for chemical stabilization to occur for anionic species making the stabilization of sulphates relatively poor compared to other cationic species.

LFA showed lower leach rates for calcium, potassium, sulphur and magnesium at any given percentage of fly ash addition, except for percentages over $70 \mathrm{wt} \%$ fly ash addition. This could be because LFA was collected from ash disposal ponds and has been in contact with water. As a result, easily soluble compounds such as calcium oxide, calcium sulphate and sodium chloride have been washed out, reducing the original high concentrations in the starting materials and making stabilization more efficient. This effect was less noticeable for heavy metal stabilization.

The maximum addition of fly ash to the geopolymer was $80 \mathrm{wt} \%$ for PFA and LFA. The criteria for maximum addition were based on the material remaining after the leaching test. The geopolymer phase is not water soluble and the stabilized fly ash geopolymer still remains after the leaching test if enough geopolymer formation has taken place. Addition of PFA and LFA at $80 \mathrm{wt} \%$ produced a minimal amount of material after the leaching test. Increasing the PFA and LFA content in the geopolymer by another $10 \mathrm{wt} \%$ did not produce any remaining geopolymer after leaching. The structural integrity of these samples was reduced such that they dissolved during the leaching test, indicating that no geopolymer formation had originally taken place and consolidation was not achieved. In fact, the reduction in structural integrity was observed at $70 \mathrm{wt} \%$ PFA and LFA, when the water content was reduced below $13.0 \mathrm{wt} \%$.

\subsection{SEM analysis}

Samples were prepared and analysed using SEM to observe the interaction between fly ash particles and the geopolymer phase. A useful tool for this is secondary electron (SE) imaging and more so backscatter electron (BSE) imaging. BSE images display elements with higher atomic masses as lighter regions of the image, more than SE images, allowing for differentiation of fly ash particles and the geopolymer. Fly ash contains elements such as calcium, iron, potassium and other heavy metals whereas the geopolymer contains atoms of relatively lower atomic mass, such as silicon, aluminium and sodium.

Figures 5 and 6 show the SE and BSE images of samples containing 20wt\% fly ash to $80 \mathrm{wt} \%$ fly ash. In Figs 5a and 6a are images of 20wt\% PFA and LFA, respectively. In these two figures there are two round particles embedded in the geopolymer phase, top left in Fig. 5a and top right in Fig. 6a. It can also be seen that particles of fly ash are distributed throughout the geopolymer and appear to be partially dissolved.

Increasing the percentage of fly ash to $40 \mathrm{wt} \%$ alters the appearance of the BSE image, as seen in Figs $5 \mathrm{~b}$ and $6 \mathrm{~b}$. Here, fly ash particles are greater in number but the geopolymer phase is still 

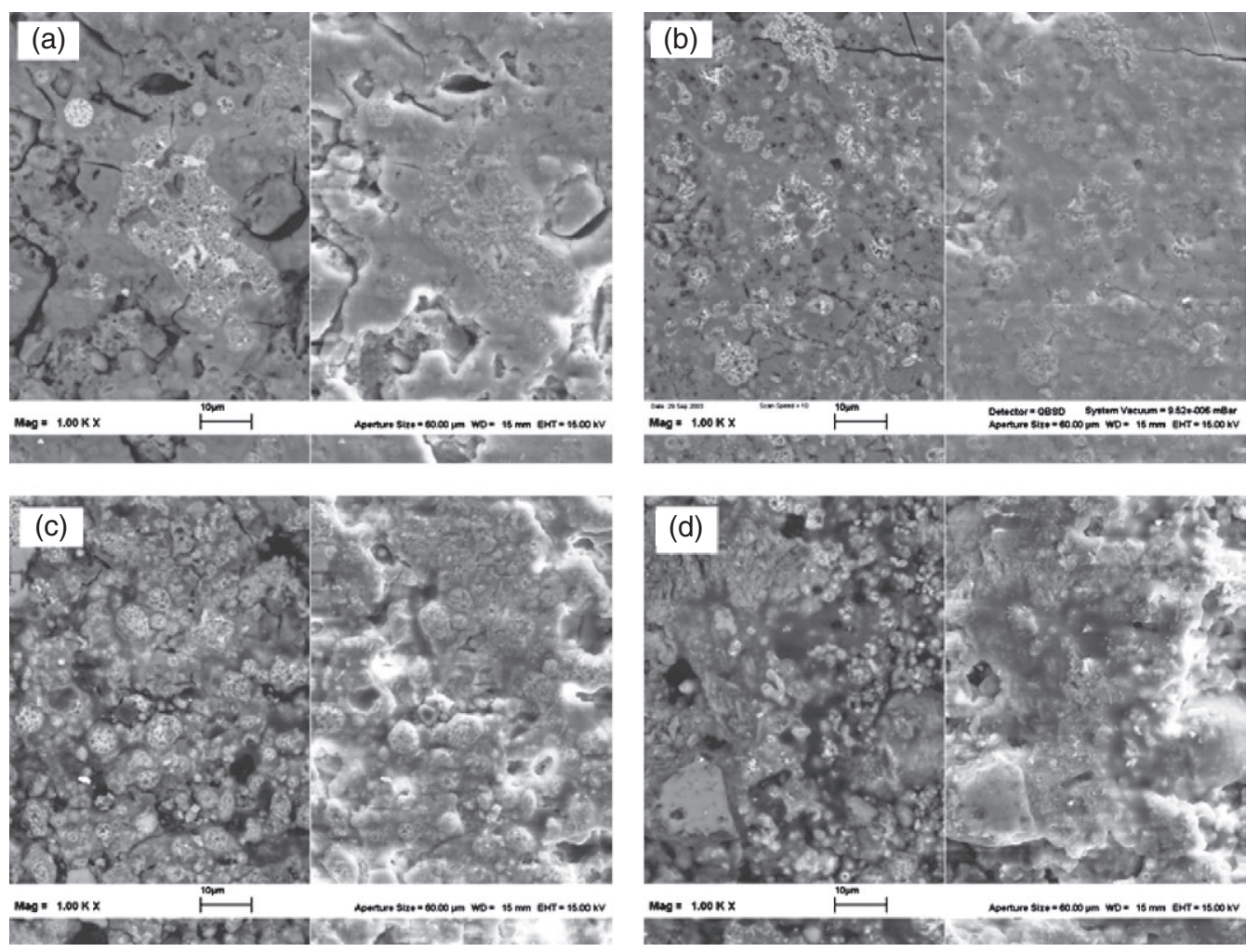

Figure 5: SEM image of PFA-geopolymer sample: (a) 20wt\% PFA, (b) 40wt\% PFA, (c) 60wt\% PFA, (d) $80 \mathrm{wt} \%$ PFA. Left, BSE image; right, SE image.

clearly visible. In Fig. $6 \mathrm{~b}$ there appears to be circular particles of significantly greater atomic mass compared to the bulk of the sample.

At 60wt \% fly ash, shown in Figs 5c and 6c, the BSE image shows the dominant phase has changed from geopolymer to fly ash. The geopolymer phase, unlike in previous SEM images of samples, which contained less fly ash, is not visible in these figures. At this percentage there is insufficient geopolymer to bind the materials; therefore, consolidation must occur through other mechanisms and not geopolymer binding.

Images of samples containing $80 \mathrm{wt} \%$ fly ash and 20wt\% geopolymer shown in Figs $5 \mathrm{~d}$ and $6 \mathrm{~d}$ appear similar to Figs $5 \mathrm{c}$ and $6 \mathrm{c}$. There is no visible geopolymer phase and the BSE image has approximately the same contrast throughout with no light or dark regions. This indicates that the dominant phase is fly ash since atomic masses of the elements in these figures are close and there is insufficient geopolymer to be detected by the BSE detector.

\subsection{Compressive strength tests}

Fly ash geopolymers were synthesized with an increasing addition of fly ash into the geopolymer network and tested for compressive strength. The results of the compressive strength tests can be seen in Fig. 7. One thing that must be considered before any discussion is that two to four samples were 

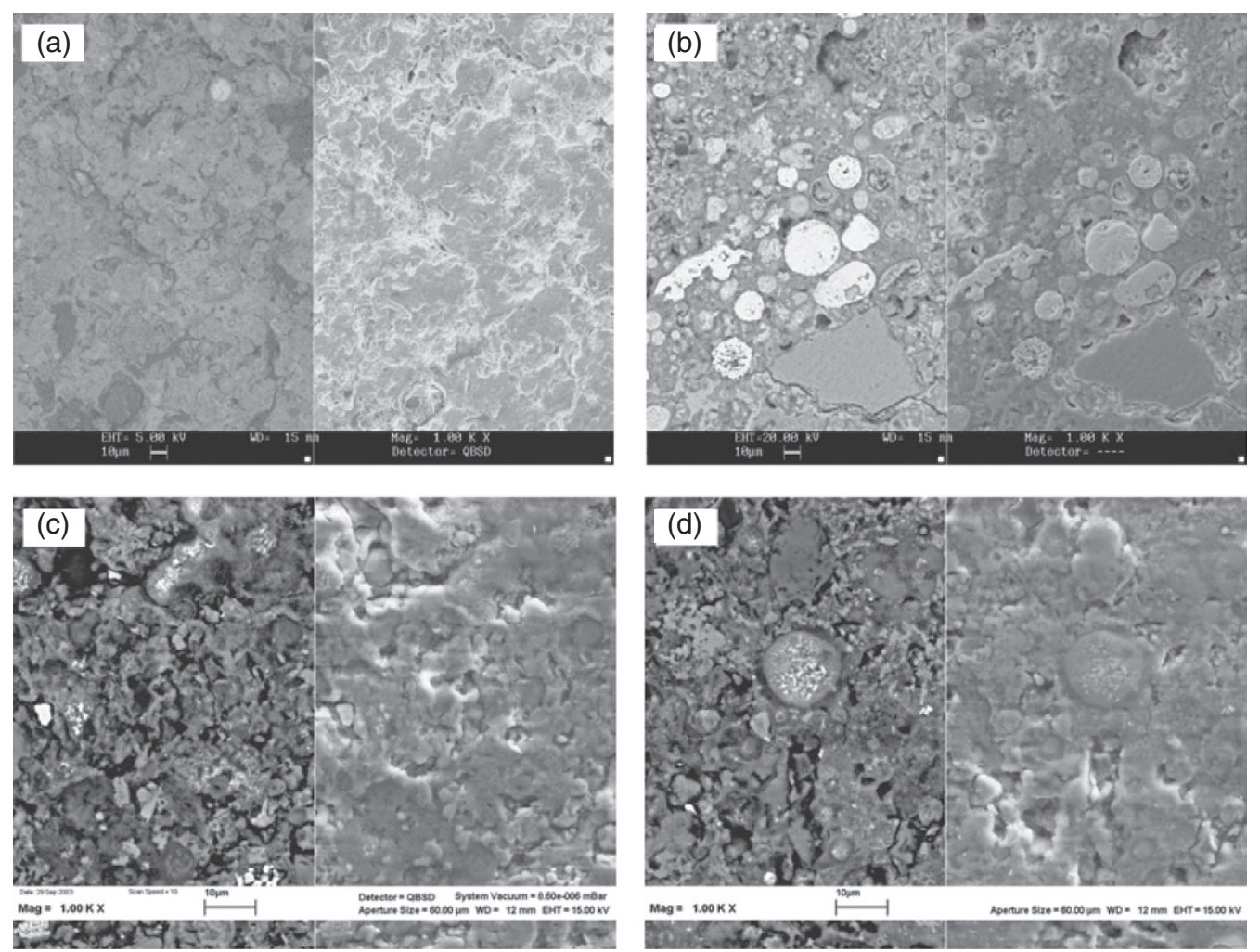

Figure 6: SEM image of LFA-geopolymer sample: (a) 20wt\% LFA, (b) 40wt\% LFA, (c) 60wt $\%$ LFA, (d) $80 \mathrm{wt} \%$ LFA. Left, BSE image; right, SE image.

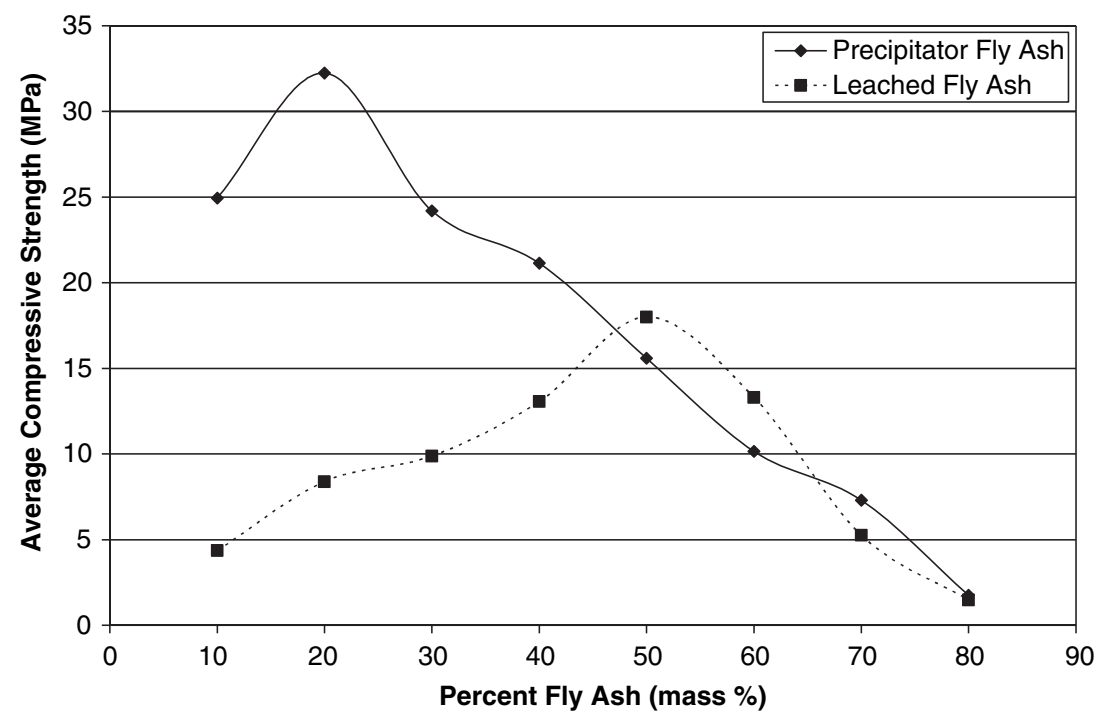

Figure 7: Maximum compressive strength of fly ash-geopolymers. 
used to create each point in Fig. 7, instead of five to six as recommended by the standard test method. The absolute compressive strength of the fly ash geopolymers is not required for this purpose and an approximate figure will suffice. The intended use of these samples is primarily the stabilization of fly ash, the strength measurements giving an indication of other potential applications.

The compressive strength curves (Fig. 7) follow a similar trend for the two types of fly ashes used in the study. The strength at low percentages of fly ash addition is low and then increases as the percentage of fly ash increases. A maximum is reached before another decrease is observed as more fly ash is added. The maximum achieved was approximately $32 \mathrm{MPa}$ for $20 \mathrm{wt} \%$ PFA addition. The same trend can be observed for LFA geopolymers although the maximum compressive strength occurred at $50 \mathrm{wt} \%$ rather than $20 \mathrm{wt} \%$ and has a magnitude of approximately $17 \mathrm{MPa}$. The decrease in strength observed at high percentages of fly ash is caused by excess fly ash in the geopolymer network. This can be related back to the SEM images of these samples which showed that samples with over $60 \mathrm{wt} \%$ fly ash were no longer geopolymeric in nature, but consisted largely of consolidated fly ash particles (Fig. 5c and d and Fig. 6c and d).

Davidovits et al. [19] stated that certain metal oxide ratios must be met in the aqueous solution for the geopolymer formation to occur and the ratios are optimized through the addition of fly ash. Van Jaarsveld et al. [12] documented that these ratio are not as critical when geopolymers are synthesized from impure materials such as fly ashes. However, by altering the cation concentration in the uncured geopolymer the strength appears to increase to some degree. PFA contains more soluble ions than LFA, which readily become available to the geopolymeric solution and therefore a greater strength increase is observed with less fly ash addition. LFA also has the ability to increase the strength of the material, although in a more limited capacity. The wet-handling operation leaches easily soluble compounds from LFA making the effect on the geopolymer less profound since the availability of cations is reduced. This could explain why the strength of LFA geopolymers is generally lower in Fig. 7, except for higher percentages.

\subsection{General considerations for reuse of geopolymer-stabilized brown coal fly ash}

Positive results of leaching tests and compressive strength tests have shown that fly ash stabilized by geopolymers with a silica to alumina molar ratio of 3 can be reused for many potential applications. Typical applications could be of a domestic nature, such as paths, driveways, bricks, pavers and garden edging. However, with further research properties of the geopolymer-stabilized fly ash could be improved to increase potential applications to the construction industry.

During the synthesis of fly ash-geopolymer samples it was noticed, although not actually measured, that the curing times of the samples decreased dramatically with increasing addition of fly ash. Phair and Van Deventer [20] have documented the catalytic effect of fly ash on curing rates of geopolymers and attributed the effect to calcium. Given that this particular fly ash contains large percentages of calcium, the catalytic effect is expected. The rate at which these samples cure is important in many applications since long curing times are unfavourable and short curing times make it difficult to handle the material prior to use. It was noticed that the time taken for the material to become difficult to handle was approximately $2 \mathrm{~h}$ for PFA samples containing $20 \mathrm{wt} \%$ PFA. This was reduced to several minutes for samples containing 40wt\% PFA. In any case the curing times are quite short and would require adjustment through the addition of specific anions, as suggested by Lee and Van Deventer [21], otherwise the material would cure before application.

The choice of fly ash used in the stabilized material must also be considered. The study of two types of fly ash has led to the conclusion that geopolymers impregnated with PFA have better properties than those with LFA. In terms of leaching, PFA has lower heavy metal leach rates and has shown 
Table 5: Material cost associated with geopolymer stabilization (AU\$) for 1500 tonnes/day of fly ash.

\begin{tabular}{lcrrr}
\hline & & \multicolumn{3}{c}{ Total cost $(\$ /$ day $)$} \\
\cline { 3 - 5 } Materials & Unit cost $(\$ /$ tonne) & Scenario 1 & Scenario 2 & Scenario 3 \\
\hline Kaolin clay & 220.00 & $\$ 53,427$ & $\$ 186,994$ & $\$ 54,762$ \\
Sodium silicate solution & 275.00 & $\$ 213,474$ & $\$ 747,160$ & $\$ 218,811$ \\
Sodium hydroxide & 5220.00 & $\$ 54,288$ & $\$ 190,008$ & $\$ 55,645$ \\
Total & & $\$ 321,189$ & $\$ 1,124,162$ & $\$ 329,218$ \\
\hline
\end{tabular}

higher compressive strengths than LFA geopolymers. However, PFA geopolymers showed faster curing times than those of LFA-geopolymers due to the higher concentration of soluble cations in PFA compared to LFA.

In terms of economic feasibility, geopolymers are still a new technology and therefore higher costs are encountered. A materials cost analysis was conducted in September 2003 to determine the cost of materials required to stabilize fly ash from one particular power station located in the Latrobe Valley. The cost analysis was conducted by assuming the materials would be purchased in Melbourne (the nearest major city) from certain chosen suppliers, and transportation costs were not included. It was also assumed that all required materials would need to be purchased, when realistically some materials may be available on site.

The results of the materials cost analysis can be seen in Table 5. Three scenarios were developed, each with a specific purpose and a throughput of 1500 tonnes/day of PFA. The aim of the first scenario is to stabilize the entire daily fly ash production rate with $40 \mathrm{wt} \%$ geopolymer making the fly ash content in the stabilized material $60 \mathrm{wt} \%$. This scenario produces a total material cost of AU\$321,189 for 1500 tonnes of PFA, which equates to a cost of AU\$214.13/tonne PFA. The second scenario focuses on the sale of the stabilized material, and so the stabilized material contains only $30 \mathrm{wt} \%$ fly ash and 70wt\% geopolymer. This scenario produced a total material cost of AU\$1,124,162 for 1500 tonnes of PFA, which yields a cost of AU\$749.44/tonne PFA. The third scenario is a combination of scenarios 1 and 2. From the total daily production of fly ash, 1wt $\%$ is stabilized and sold using scenario 2 and the remaining percentage $(99 \mathrm{wt} \%)$ is stabilized using scenario 1 . The total materials cost for this scenario was AU\$329,218, which produced a cost of AU\$219.48/tonne PFA. However, since only $1 \%$ of the daily fly ash production is converted into value-added products, these can be sold to recover costs of the stabilization process.

\section{CONCLUSION}

In this study brown coal fly ash was stabilized by a geopolymer with a molar silica to alumina ratio of 3. Two types of fly ash were used which were collected from different stages of a fly ash disposal process. Each sample was subjected to a standard leaching test and compressive strength tests. These two tests would determine whether the stabilized material is suitable for the manufacture of value-added products by having low leach rates for heavy metals and adequate compressive strength. It was found that the geopolymer has the ability to reduce the leach rates of many of the elements in the fly ash and at the same time produce a material with good compressive strength. Best stabilization results were obtained for calcium, potassium, barium, copper, molybdenum and strontium in PFAgeopolymer samples. LFA showed lower leaching rates of major elements than PFA, a result of the 
wet handling process used to transport the fly ash to the ash pond. Contrary to this PFA showed lower leach rates for trace metals.

The maximum compressive strength of the fly ash geopolymers was tested and found to be $32 \mathrm{MPa}$ for the $20 \mathrm{wt} \%$ PFA and $80 \mathrm{wt} \%$ geopolymer mix. PFA-geopolymer materials were found to develop high strength at low additions of fly ash and the strength decreased as the percentage of fly ash increased. LFA samples developed high strength at higher additions of fly ash. The difference was attributed to the greater dissolution of compounds and ions from PFA during synthesis as opposed to LFA. The lower content of soluble ions in LFA is a result of sluicing to transport and store PFA in ash ponds. SEM was used to link the leach rates at various percentages of fly ash addition with compressive strength data and to understand the mechanisms of binding and fly ash interaction with the geopolymer.

Cost estimation was conducted to determine the material costs that would be encountered if a geopolymeric material was used to stabilize brown coal fly ash. Three scenarios were proposed, which produced two different products. Scenario 1 was proposed for the stabilization of the fly ash only, scenario 2 for the sale of value-added products only and a third scenario that produced a combination of both.

\section{ACKNOWLEDGEMENTS}

The authors gratefully acknowledge the APAI scholarship provided by the ARC Linkage scheme as well as support and contributions from International Power Hazelwood, Monash University, Churchill and Blue Circle Southern Cement, Waurn Ponds.

\section{REFERENCES}

[1] Barber, E.G., Jones, G.T., Knight, P.G.K. \& Miles, M.H., PFA Utilization, Central Electricity Generation Board, Gibbons: Wolverhampton, pp. 17-74, 1973.

[2] Black, C. et al., Utilisation of Latrobe Valley brown coal fly ash. Gippsland Basin Symposium, Melbourne, 1992.

[3] Iyer, R.S. \& Scott, J.A., Power station fly ash-a review of value added utilization outside of the construction industry. Resources, Conservation and Recycling, 31(3), pp. 217-228, 2001.

[4] Davidovits, J., Geopolymers: inorganic polymeric new materials. Journal of Thermal Analysis, 37, pp. 1633-1656, 1991.

[5] Van Jaarsveld, J.G.S. \& Van Deventer, J.S.J., The effect of metal contaminants on the formation and properties of waste-based geopolymers. Cement and Concrete Research, 29(8), pp. 11891200, 1999.

[6] Barbosa, V.F.F., MacKenzie, K.J.D. \& Thaumaturgo, C., Synthesis and characterisation of materials based on inorganic polymers of alumina and silica: sodium polysialate polymers. International Journal of Inorganic Materials, 2(4), pp. 309-317, 2000.

[7] Van Jaarsveld, J.G.S., Van Deventer, J.S.J. \& Lorenzen, L., Factors affecting the immobilisation of metals in geopolymerised fly ash. Metallurgical and Materials Transaction B, 29, pp. 283291, 1998.

[8] Van Jaarsveld, J.G.S., Van Deventer, J.S.J. \& Schwartzman, A., The potential use of geopolymeric materials to immobilise toxic metals: Part II. Materials and leaching characteristics. Minerals Engineering, 12(1), pp. 75-91, 1999.

[9] Alonso, S. \& Palomo, A., Alkaline activation of metakaolin and calcium hydroxide mixtures: influence of temperature, activator concentration and solids ratio. Materials Letters, 47(1-2), pp. 55-62, 2001. 
[10] Purdon, A.O., The action of alkalis on blast furnace slag. Journal of the Society of the Chemical Industry, 59, pp. 191-202, 1940.

[11] Xu, H. \& Van Deventer, J.S.J., The geopolymerisation of alumino-silicate minerals. International Journal of Mineral Processing, 59(3), pp. 247-266, 2000.

[12] Van Jaarsveld, J.G.S., Van Deventer, J.S.J. \& Lorenzen, L., The potential use of geopolymeric materials to immobilise toxic metals: Part I. Theory and applications. Minerals Engineering, 10(7), pp. 659-669, 1997.

[13] Khalil, M.Y. \& Merz, E., Immobilisation of intermediate-level wastes in geopolymers. Journal of Nuclear Materials, 2(1), pp. 141-148, 1994.

[14] Palomo, A. \& Lopez de la Fuente, J.I., Alkali-activated cementitious materials: alternative matrices for the immobilisation of hazardous wastes. Part 1. Stabilisation of boron. Cement and Concrete Research, 33(2), pp. 281-288, 2003.

[15] Palomo, A. \& Palacios, M., Alkali-activated cementitious materials: alternative matrices for the immobilisation of hazardous wastes. Part 2. Stabilisation of chromium and lead. Cement and Concrete Research, 33(2), pp. 289-295, 2003.

[16] USEPA, Toxicity Characteristic Leaching Procedure, Methods 1311, 1992.

[17] Standards Australia, Method of testing Portland, blended and masonry cements, Method 11: Compressive strength, pp. 1-9, 2001.

[18] Victorian EPA, Publication 448: Classification of Wastes, Victorian EPA: Melbourne, pp. 1-6, 1995.

[19] Davidovits, J., Davidovits, M. \& Davidovits, N., Process for obtaining a geopolymeric aluminosilicate and the products thus obtained, US Pat. No. 5,342,595, 1994.

[20] Phair, J.W. \& Van Deventer, J.S.J., Effect of the silicate activator pH on the microstructural characteristics of waste-based geopolymers. International Journal of Mineral Processing, 66(1-4), pp. 121-143, 2002.

[21] Lee, W.K.W. \& Van Deventer, J.S.J., The effect of ionic contaminants on the early-age properties of alkali activated fly ash-based cements. Cement and Concrete Research, 32(4), pp. 577-584, 2002. 